\title{
Coincidencia de dos entidades infrecuentes
}

\section{Association of two infrequent diseases}

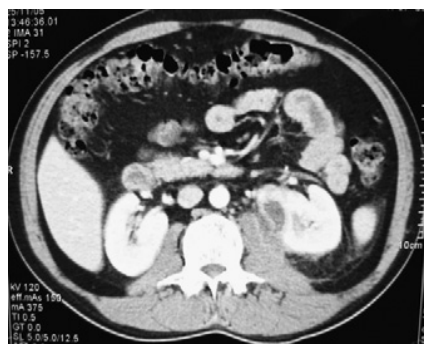

Imagen 1 - TAC, corte transversal. Colección que afecta al músculo psoas izquierdo borrando los límites. Foco de pielonefritis en el hemirriñón del mismo lado.

J. Navarro Gil*, J. Subirá Ríos, J. García-Magariño Alonso,

D. García Calero, J.M. Sánchez Zalabardo y J. Valdivia Uría

Servicio de Urología, Hospital Clínico Universitario Lozano Blesa, Zaragoza, España

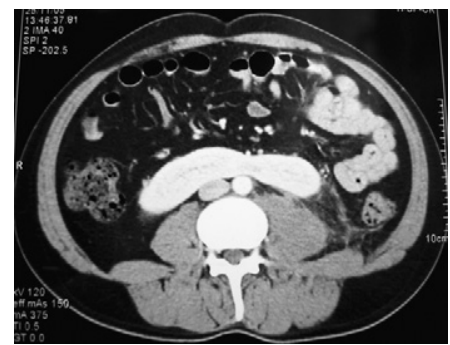

Imagen 2 - TAC, corte transversal. Fusión de los polos inferiores de ambos hemirriñones. A este nivel aún se observa el borramiento de los límites del psoas.

*Autor para correspondencia

Correo electrónico: telonman@hotmail.com (J. Navarro Gil)

\section{Retención aguda de orina en paciente con antecedente de prostatectomía radical}

\section{Urinary retention in a patient with antecedents of radical prostatectomy}

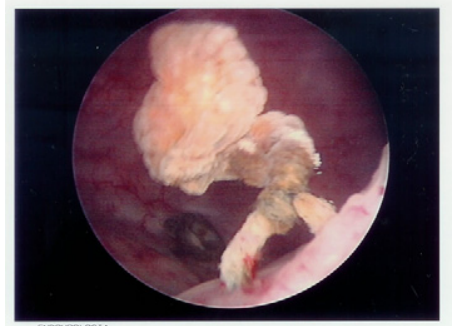

Foto 1 - Hilo de sutura reabsorbible calcificada, en horario 5 de cuello vesical.

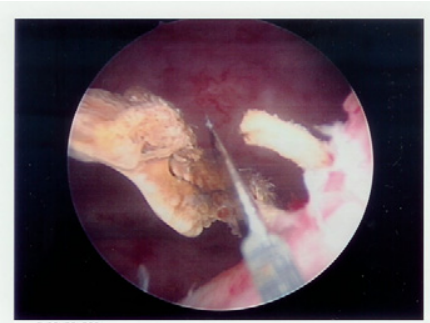

Foto 2 - Sección mediante cuchillete.
J. Subirá Ríos*, B. Blasco Beltrán, J. García-Magariño Alonso,

D. García Calero y J.G. Valdivia Uría

Servicio de Urología, Hospital Clínico Universitario Lozano Blesa, Zaragoza, España

\footnotetext{
*Autor para correspondencia.

Correo electrónico: kokedoc@hotmail.com (J. Subirá Ríos)
}

doi: 10.1016/j.acuro.2010.02.013 